\title{
Estudio etnomicológico de Melanogaster variegatus (Vittad.) Tul. \& C. Tul. en la Región de Murcia (España)
}

\author{
(Ethnomicological study of Melanogaster variegatus (Vittad.) \\ Tul. \& C. Tul. in the Region of Murcia (Spain))
}

Francisco F. Cano Trigueros Investigador independiente.

Autor para correspondencia: montepardo@hotmail.com

RECIBIDO: 14 de Octubre de 2019

APROBADO: 18 de Noviembre de 2019

DOI: 10.22370/bolmicol.2019.34.2.1956

EL AUTOR DECLARA NO TENER CONFLICTO DE INTERESES

Palabras claves: alimentos silvestres; Cistus; etnobotánica; etnomicología; Melanogaster variegatus. Key words: wild foods; Cistus; ethnobotany; ethnomicology; Melanogaster variegatus.

\section{RESUMEN}

En este trabajo se muestra el conocimiento etnomicológico del hongo Melanogaster variegatus (Vittad.) Tul. \& C. Tul. recopilado en el ámbito territorial de la Región de Murcia (España) mediante entrevistas presenciales a la población local realizadas con una metodología etnobotánica, incluyendo su relación simbiótica con las plantas del género Cistus. También contiene alguna reflexión sobre el uso de estos conocimientos para la investigación científica y el manejo del medio natural, sobre la regulación moderna del recurso micológico en nuestro territorio, así como del necesario mantenimiento de los aprovechamientos tradicionales practicados racionalmente.

\section{ABSTRACT}

This work shows the ethnomycological knowledge of the fungus Melanogaster variegatus (Vittad.) Tul. \& C. Tul. compiled in the territorial area of the Region of Murcia (Spain) by means of face-to-face interviews with the local population achieved through an ethnobotanical methodology, including symbiotic relacionships with the plants of the Cistus genus. This also contains some reflections about the use of this knowledge for scientific research and the management of the mycological resource in our territory, as well as regarding the necessary maintenance of traditional uses rationally practiced.

\section{INTRODUCCION}

Una derivada no infrecuente del trabajo de campo etnobiológico es el descubrimiento, en un territorio concreto, de la presencia de especies biológicas de las que no se tenía constancia previa en el ámbito científico-académico. Algo así le sucedió al autor del presente artículo en una de las primeras entrevistas etnobotánicas en profundidad que realizó en la Región de Murcia y que contribuyó a confirmar el profundo conocimiento de algunas 
personas sobre su medio natural. Fue en 1991, en el municipio de Cartagena, donde Antonio Liarte, gran persona y excepcional conocedor de su medio, puso sobre la pista de algo desconocido para el autor hasta ese momento y de lo que no existían citas científicas para la zona: "El Día de San Fulgencio (...) ibamos a coger huevos del juagarzo". De la descripción que hizo Antonio de este producto comestible de los montes de su entorno se podía intuir que esos huevos serían posiblemente hongos hipogeos ligados a esta planta, cuya identidad taxonómica se concretaría poco después, a través de la información recopilada de otros informantes, aunque pasaron algunos años hasta que, vistas ya muestras de este producto se confirmaron definitivamente las suposiciones iniciales.

Melanogaster es un género de hongos gasteroides, del Orden Boletales, que agrupa a diferentes especies fúngicas hipogeas o semihipogeas, siendo Melanogaster variegatus (Vittad.) Tul. \& C. Tul. la especie más común del género. Se trata de un hongo hipogeo o semihipogeo del que se refiere que establece simbiosis ectomicorrícica con una amplia variedad de especies arbóreas (Géneros Quercus, Abies, Fagus, Corylus, Castanea, Alnus, Pinus, Larix, Cedrus, Picea...) y arbustivas (Cistus, Juniperus, Quercus...), habitando en suelos muy variados, tanto de tipo básico como ácido.

Su distribución geográfica es cosmopolita, citándose en Europa, Norte de África y Norteamérica. En la base de datos GBIF (Global Biodiversity Information Facility) se recoge su presencia, además de en España, en: Noruega, Austria, Estonia, Suecia, Reino Unido, Alemania, Bélgica, Eslovenia, Hungría, Francia, Italia, Rusia (parte europea), Eslovaquia, Portugal, Letonia, USA, Canadá, Argelia, Túnez y una cita puntual en México. Además, también se ha citado en Marruecos, Rumanía, Bulgaria, Lituania, Polonia, Grecia y Turquía.

Sus basidiocarpos son fácilmente identificables, apareciendo, generalmente, en grupos nu- merosos. Su tamaño más habitual oscila entre 2 y 6 $\mathrm{cm}$ de diámetro, aunque se encuentran ejemplares de menor o mayor tamaño. Su forma es variable, desde subglobosa a irregular, con rizomorfos recorriendo su superficie. El peridio (piel) muestra un color pardo-amarillento cuando es joven y aspecto ferruginoso que oscurece con la madurez. La gleba (carne) tiene una textura gelatinosa, de color amarillento al principio y negro alquitrán después, constituida de cámaras subpentagonales de paredes amarillentas o blancas que conforman una característica venosidad y que se licuan en la madurez. Las basidiosporas son anchamente elipsoidales a ovaladas de 7-10 x 5-7 $\mu \mathrm{m}$., de paredes gruesas y lisas (Moreno, Gómez \& Pulido, 2005). Presenta un olor intenso característico que recuerda al regaliz.

En cuanto a su comestibilidad, la bibliografía consultada recoge una serie de afirmaciones vagas y, en algunos casos, contradictorias. No obstante, en una mayor proporción, se señala que se trata de un hongo comestible, sin grandes cualidades gastronómicas, desaconsejándose, en algún caso, el consumo de ejemplares maduros. En la búsqueda efectuada a nivel bibliográfico y documental, no se ha localizado información alguna sobre su posible recolección y consumo tradicional en España. En otros países, las referencias a este aprovechamiento tradicional también son escasas y poco precisas. La cita más destacada es la de su venta en el siglo XIX en los mercados de la ciudad de Bath (Inglaterra) como "trufa roja" (Broome, 1871).

En el continente americano, en México, Carl Lumholtz recoge la recolección tradicional como alimento por los indígenas tarahumares de una especie identificada inicialmente como $\mathrm{Me}$ lanogaster variegatus var mexicanus (Lumholtz, 1904) y que, más tarde, se reclasificó como Melanogaster umbriniglebus Trappe \& Guzman (Trappe \& Guzman, 1971).

Actualmente, existe alguna empresa que comercializa esta especie. Así, por ejemplo, la 
Estudio etnomicológico de Melanogaster variegatus (Vittad.) Tul. \& C. Tul. - Cano F.

compañía rumana Truffoir las incluye en su catálogo de productos con el nombre de "trufa con sabor a baya silvestre" o "trufa roja", estando disponible desde julio a octubre y señalándose su utilización en aperitivos y postres como, por ejemplo, helados (www.truffoir.ro, consultada en 2018).

Dejando a un lado unas pocas referencias a la presencia de este hongo en nuestro país en algunas obras científicas del siglo XIX y comienzos del siglo XX, ya avanzado este último siglo esta especie se ha ido citando cada vez con más frecuencia conforme se incrementaba el conocimiento micológico de nuestro territorio, evidenciándose su presencia en gran parte de las regiones peninsulares españolas (Tabla 1). Del análisis de las fechas de extracción de los ejemplares citados en estas publicaciones se desprende que los basidiocarpos pueden aparecer (dentro del territorio donde habita esta especie en España y sumando globalmente todas de localidades citadas) a lo largo de todo el año aunque las estaciones más habituales, por orden de preferencia, son: primavera, otoño, invierno y verano.

Como plantas que establecen simbiosis micorrícica con $M$. variegatus en nuestro país se han señalado o sugerido (con desigual grado de precisión o rigor), sobre todo, especies de la familia de las fagáceas y de las cistáceas, aunque no únicamente (Tabla 1).

Tabla 1. Regiones administrativas españolas con presencia de M. variegatus.

\begin{tabular}{|c|c|c|}
\hline $\begin{array}{c}\text { REGIÓN } \\
\text { (Provincias) }\end{array}$ & $\begin{array}{l}\text { PLANTAS SIMBIONTES } \\
\text { O RELACIONADAS }\end{array}$ & REFERENCIAS \\
\hline $\begin{array}{l}\text { Andalucia (Almería, } \\
\text { Cádiz, Córdoba, } \\
\text { Granada, Huelva, } \\
\text { Jaén, Málaga, } \\
\text { Sevilla) }\end{array}$ & $\begin{array}{l}\text { Castanea sativa, Cistus } \\
\text { albidus, C. ladanifer, Larix } \\
\text { decidua, Pinus pinea, } \\
\text { Quercus sp, Quercus ilex } \\
\text { subsp ballota, Q. suber }\end{array}$ & $\begin{array}{c}\text { Romero de la Osa, } 1993 \\
\text { Moreno-Arroyo et al., } \\
1999 \\
\text { Moreno-Arroyo } \\
\text { (Coord.), } 2004\end{array}$ \\
\hline $\begin{array}{l}\text { Aragón (Huesca, } \\
\text { Teruel) }\end{array}$ & Quercus ilex subsp. ballota & $\begin{array}{c}\text { HDCJBM, } 1992 \\
\text { Barriuso, } 2011\end{array}$ \\
\hline Asturias & $\begin{array}{l}\text { Fagus sylvatica, Quercus } \\
\text { robur, Q. ilex, Corylus } \\
\text { avellana }\end{array}$ & $\begin{array}{c}\text { García, } 2004 \\
\text { Rubio et al., } 2006\end{array}$ \\
\hline $\begin{array}{l}\text { Islas Baleares (Ibiza, } \\
\text { Mallorca, Menorca) }\end{array}$ & $\begin{array}{c}\text { Pinus halepensis, Pistacia } \\
\text { lentiscus, Quercus ilex subsp } \\
\text { ballota }\end{array}$ & $\begin{array}{c}\text { Barcelo, 1879-81 } \\
\text { Calonge et al., } 1988 \\
\text { Calonge et al., } 1992 \\
\text { Calonge et al., } 1993 \\
\text { Siquier et al, } 2005 \\
\text { Siquier et al., } 2015 \\
\end{array}$ \\
\hline $\begin{array}{l}\text { Cataluña (Barcelona, } \\
\text { Gerona, Lérida) }\end{array}$ & $\begin{array}{c}\text { Quercus cocifera, } Q . \text { ilex, } Q \text {. } \\
\text { suber, Pinus halepensis, } P . \\
\text { sylvestris, Cistus clussi, } C \text {. } \\
\text { monspeliensis, C. } \\
\text { salviifolius, Ulex parviflorus }\end{array}$ & $\begin{array}{c}\text { Llimona et al, } 2000 \\
\text { Maire, } 1937 \\
\text { Tabares et al., } 1991 \\
\text { Vidal, } 1991 \\
\text { Vila et al., } 2002 \\
\text { Vila et al., } 2006 \\
\end{array}$ \\
\hline Cantabria & Quercus ilex, $Q$. pyrenaica & Paz, 2013 \\
\hline $\begin{array}{l}\text { Castilla la Mancha } \\
\text { (Albacete, Cuenca, } \\
\text { Guadalajara) }\end{array}$ & $\begin{array}{l}\text { Pinus pinea, Quercus } \\
\text { rotundifolia, } Q . \text { ilex, } Q . \\
\text { faginea, } Q . \text { pyrenaica }\end{array}$ & $\begin{array}{c}\text { Calonge, } 1973 \\
\text { HDCJBM, } 1998 \\
\text { Marcos, } 2017\end{array}$ \\
\hline
\end{tabular}


Estudio etnomicológico de Melanogaster variegatus (Vittad.) Tul. \& C. Tul. - Cano F.

\begin{tabular}{|c|c|c|}
\hline $\begin{array}{l}\text { Castilla y León } \\
\text { (Burgos, León, } \\
\text { Segovia, Soria, } \\
\text { Valladolid, Zamora) }\end{array}$ & $\begin{array}{l}\text { Pinus pinea, Quercus ilex, } Q \text {. } \\
\text { faginea, Cistus laurifolius }\end{array}$ & $\begin{array}{c}\text { Mendaza et al., } 1987 \\
\text { Cabero et al., } 2015 \\
\text { Calonge, } 1993 \\
\text { HDCJBM, } 1995 \\
\text { Bregón, 2013 } \\
\text { García, 2013 } \\
\end{array}$ \\
\hline Extremadura & $\begin{array}{l}\text { Cistus sp, C. albidus, } \\
\text { Quercus rotundifolia }\end{array}$ & $\begin{array}{l}\text { Gelpi et al., } 2013 \\
\text { Micoex, } 2016\end{array}$ \\
\hline Galicia (La Coruña) & & $\begin{array}{c}\text { Sobrado, } 1911 \\
\text { Castro et al., } 1993 \\
\end{array}$ \\
\hline La Rioja & Quercus ilex & $\begin{array}{c}\text { HDCJBM, } 1988 \\
\text { Calonge, } 1992 \\
\end{array}$ \\
\hline Madrid & & HDCJBM, 1984 \\
\hline Murcia & Cistus clusii & Honrubia, 1992 \\
\hline Navarra & & HDCJBM, 1998 \\
\hline $\begin{array}{c}\text { País Vasco } \\
\text { (Vizcaya, } \\
\text { Guipuzcoa, Alava) }\end{array}$ & $\begin{array}{c}\text { Juniperus communis, } \\
\text { Quercus ilex, Q. rotundifolia }\end{array}$ & $\begin{array}{c}\text { Lazaro, 1911 } \\
\text { Picón et al., } 2007 \\
\text { Fernández et al., } 2013 \\
\text { Aldama, } 2018 \\
\end{array}$ \\
\hline $\begin{array}{l}\text { Valencia (Alicante, } \\
\text { Castellón, Valencia) }\end{array}$ & $\begin{array}{c}\text { Cistus monspeliensis, } C . \\
\text { albidus, Quercus coccifera, } \\
\text { Q. ilex, Q. faginea, Juniperus } \\
\text { oxycedrus }\end{array}$ & $\begin{array}{c}\text { Bosca, } 1873 \\
\text { Mahiques et al., } 1995 \\
\text { Sánchez et al., } 1995 \\
\text { García et al., } 1996 \\
\text { Tejedor et al., } 2008 \\
\text { Conca et al., } 2015 \\
\end{array}$ \\
\hline
\end{tabular}

Las plantas de la familia de las cistáceas constituyen un componente importante del paisaje vegetal en la región mediterránea. Dentro de la misma destaca el género Cistus, que le da nombre y juega un papel destacado como planta simbionte de nuestro hongo. De acuerdo con modernos estudios filogenéticos (Guzman \& Vargas, 2005), este género botánico incluye 21 especies de plantas arbustivas que habitan en esta región y se encuentran perfectamente adaptadas a climas áridos y pobres condiciones edáficas. Se presentan en nuestros montes bien como integrantes del sotobosque forestal o bien constituyendo formaciones de matorral con mayor o menor grado de pureza específica o mezcla con otras plantas, tanto en suelos ácidos como neutros o básicos. En la Península Ibérica e Islas Baleares habitan 12 de las especies que incluye este género y 8 en la Región de Murcia (Castroviejo et al., 2003).
La importancia de este género, en cuanto a su asociación con hongos de diversa adscripción taxonómica, ha sido puesta de manifiesto, sobre todo, en este siglo XXI, publicándose cada vez más investigaciones que la refuerzan. Así, se han señalado hasta 300 especies de macromicetos relacionadas con Cistus, 35 de las cuales, como mínimo, parecen ser específicas del huésped (Loizides $\&$ Kyriakou, 2011). En un estudio recopilatorio de 2006, se señalaba, al menos, 200 especies de hongos pertenecientes a 40 géneros como establecedoras de simbiosis micorrícica con Cistus (Comandii, 2006), con un buen número de especies comestibles (Oria de Rueda et al., 2008).

La Región de Murcia es una unidad administrativa territorial de España coincidente, en buena parte, con el antiguo Reino de Murcia. Se haya situada en el sureste de la Península Ibérica 
y ocupa una extensión de $11.314 \mathrm{~km}^{2}$, con 274 kilómetros de costa (170 si exceptuamos la laguna litoral denominada Mar Menor). Ubicada dentro del dominio de las Cordilleras Béticas, presenta un relieve variado donde se alternan zonas montañosas con llanuras y valles y zonas costeras.

Su geología es compleja aunque predominan los materiales carbonatados. Las montañas son mayoritariamente de naturaleza calizo-dolomítica, salvo las litorales y prelitorales donde abundan pizarras, esquistos y cuarcitas. Sin embargo, las depresiones están dominadas por terrenos margoyesíferos o margo-salinos, con abundantes materiales aluviales en las cuencas fluviales. Sus suelos son generalmente poco evolucionados, sobre todo en las zonas litorales, pobres en materia orgánica y alto contenido en carbonato cálcico, aunque el sustrato geológico del que derive, topografía y manejo humano condicionará sus características concretas.

Su clima es de tipo mediterráneo, con inviernos suaves y cortos y veranos calurosos. Las precipitaciones son escasas e irregulares, con una media anual que sobrepasa algo los $300 \mathrm{~mm}$ aunque con importantes diferencias territoriales (entre 200 y $700 \mathrm{~mm}$, correspondiendo las menores precipitaciones a las zonas litorales), siendo más abundantes en otoño y muy infrecuentes en verano. Las temperaturas son muy elevadas en verano y no muy frías en invierno, con una media anual que varía, según la altitud, entre los $16^{\circ}$ y $19^{\circ} \mathrm{C}$. Las heladas hacen su aparición en pocas ocasiones, salvo en las comarcas situadas más al norte del territorio. La insolación es muy alta, con alrededor de 3.000 horas de sol anuales, lo que propicia unos altos índices de evapotranspiración.

La diversidad de su flora vascular silvestre es elevada, superando las 2.000 especies, con un importante número de endemismos e iberoafricanismos (Alcaraz et al., 2008). Su vegetación natural es variada aunque, por las escasas precipita- ciones, predominan las formaciones de matorral, siendo ya más frecuentes las formaciones arbóreas en las sierras interiores con predominio de pinares de Pinus halepensis Miller.

Por su parte, el componente fúngico inventariado lo forman 575 especies (Honrubia et al., 2018) aunque la cantidad real probablemente sea bastante superior. Por tratarse de una zona eminentemente árida, son escasos los momentos en los que se pueden observar en ella producciones elevadas de setas u hongos. No obstante, las especies hipogeas presentes en el territorio consiguen eludir esta aridez mediante estrategias como fructificar debajo del suelo (Manovel, 2012), considerándose este hábito una adaptación al calor y sequía de los ecosistemas mediterráneos (Díez, Manjon \& Martin, 2002) jugando un importante papel en el mantenimiento de los mismos.

De todas estas especies que integran la micobiota murciana, hasta el momento, se ha recogido información sobre el aprovechamiento popular tradicional en la Región de Murcia de setas u hongos pertenecientes, al menos, a 15 géneros, de los cuales tuvieron un papel destacado a nivel cuantitativo y desde una perspectiva regional, sobre todo, 3 de ellos: Lactarius (Sección Dapetes), Pleorotus y Terfezia.

Al margen de otras posibles especies de otros géneros que hayan podido ser consumidas esporádicamente por su parecido con las popularmente recolectadas, el género Melanogaster es uno de los tres géneros de hongos hipogeos objeto de recolección tradicional en la Región de Murcia, junto con Terfezia y Picoa (Cano, 2003), conocidas popularmente las especies pertenecientes a estos dos últimos géneros en nuestro territorio mayoritariamente como turmas y peos de zorra, respectivamente, estableciendo simbiosis micorrícica con las plantas del género Helianthemum, conocidas frecuentemente en la zona como matas turmeras (Figura 1). 


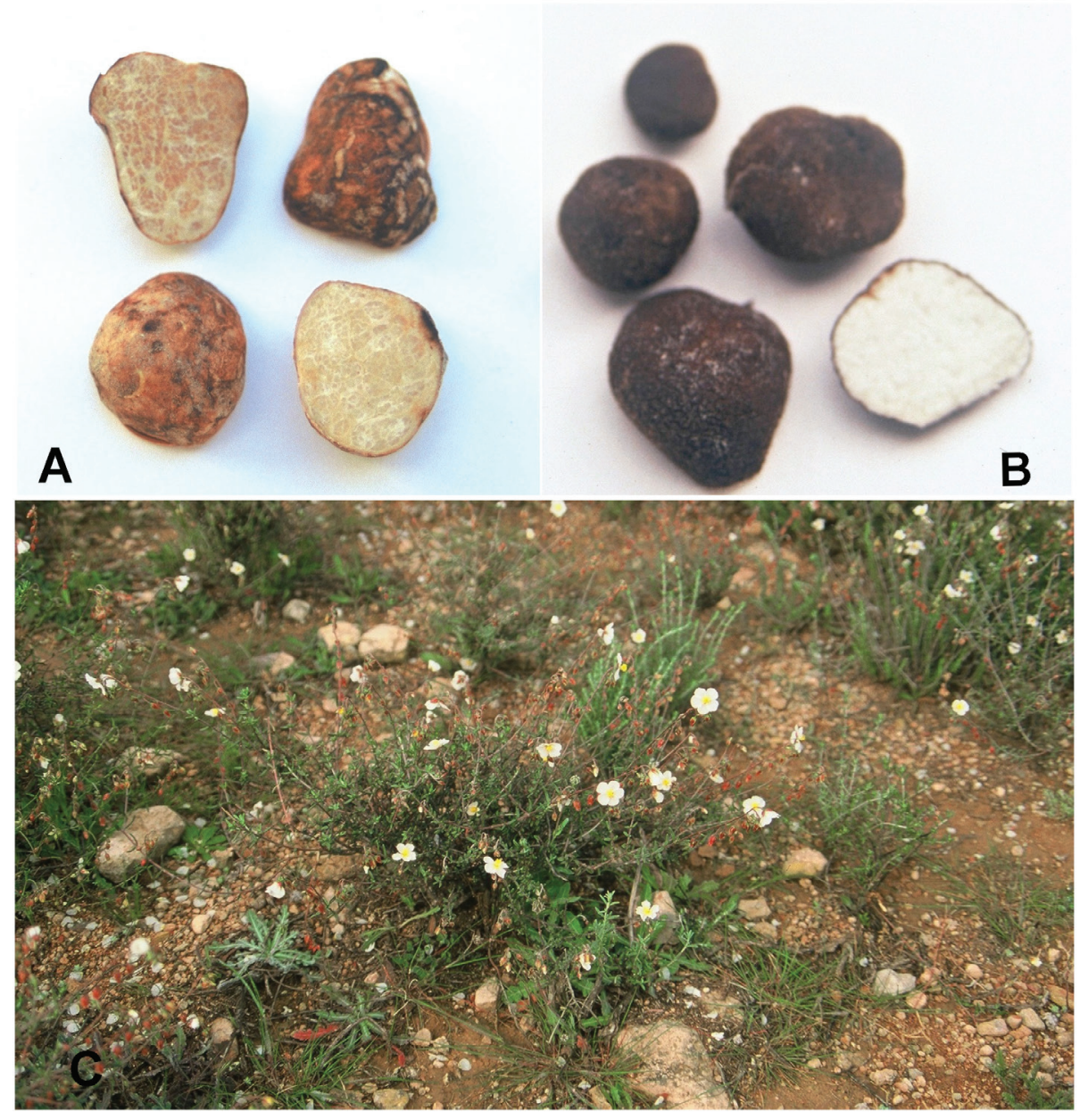

Figura 1. A) Turmas B) Peos de zorra C) Matas turmeras.

\section{MATERIALES Y MÉTODOS}

La información utilizada para la elaboración del presente trabajo procede de entrevistas etnobotánicas presenciales realizadas a informantes locales de la Región de Murcia, llevadas a cabo de manera discontinua entre 1991 y 2013, tanto de forma individual como en forma de entrevista grupal (familiar o no) a un máximo de tres personas, bien de forma puntual o repetidas en años sucesivos. Como base de las mismas se empleó, en algunas de ellas, un cuestionario diseñado previamente que contenía diferentes preguntas relacionadas con la temática, aunque se utilizó con la necesaria flexibilidad para no condicionar el discurso espontáneo de los informantes o para introducir, sobre la marcha, nuevas temáticas. Bien de forma previa o en su transcurso, se informó a los informantes del objetivo de la entrevista y, antes de realizar alguna fotografía con imágenes personales de los mismos, se solicitó su permiso previo.

Las entrevistas se llevaron a cabo con el fin de obtener específicamente información de este aprovechamiento o, en otros casos, en el marco de una entrevista más general dirigida a recopilar información etnobotánica diversa. En otras ocasiones se desarrollaron en las propias zonas de recolección o existió algún acompañamiento a éstas para mostrarme el producto en sí, sus plantas simbiontes $\mathrm{u}$ otros aspectos relacionados con su aprovechamiento. La información recogida en las mismas fue 
objeto posterior de detallado y pausado análisis e interpretación, teniendo en cuenta tanto la visión de la población participante como su interpretación desde una perspectiva etnográfica y científico-académica.

Un total de 46 personas, 38 hombres y 8 mujeres, aportaron información sobre este aprovechamiento. De ellas, 1 nació en la década de los años 10 del siglo pasado, 8 en la década de los años 20, 13 en la década de los 30, 14 en la década de los 40, 6 en la década de los 50, 2 en la década de los 60,1 en la década de los 70 y 1 en la década de los 80. La amplitud, profundidad y detalle de los datos aportados por los informantes fue desigual, constituyendo los contenidos incluidos en el presente artículo una síntesis del conjunto de informaciones o percepciones recogidas correspondiendo, no obstante, algunas de ellas, sólo a unas pocas personas con elevada capacidad de observación individual o que se han interesado en conocer los saberes procedentes de otras generaciones.

Además, también fueron consultadas buena parte de las entrevistas etnobotánicas presenciales llevadas a cabo por el autor en otras zonas no litorales o prelitorales de la Región donde crecen algunas las especies del género Cistus con las que establece micorrizas nuestro hongo. En todas ellas, al ser preguntados los informantes, se obtuvieron respuestas negativas respecto al aprovechamiento o conocimiento de este $\mathrm{u}$ otros hongos hipogeos asociados al mismo.

Aparte de entrevistas etnobotánicas, también se llevó a cabo en diferentes años una prospección botánica sin acompañantes en algunas zonas dentro de su área de recolección tradicional, recogiéndose algunas muestras del hongo y de las plantas simbiontes para su estudio macroscópico y clasificación taxonómica.

Por otra parte, se efectuó una revisión de bibliografía científica antigua y actual, una revisión bibliográfica en obras de materias varias (historia, etnografía, prensa local...) buscando posibles menciones de este producto, además de realizar un pequeño muestreo documental en algunos archivos históricos de la Región de Murcia.

\section{RESULTADOS}

Primeramente, indicar que la información se obtuvo solamente de las encuestas realizadas y no así de las búsquedas bibliográfica y documental sobre la zona de estudio, de la que no se obtuvo ningún dato sobre el conocimiento o aprovechamiento tradicional de este producto, más allá de un par de escuetas menciones sin interés en algún libro costumbrista local.

\section{Denominaciones populares. Identificación de basidiocarpos y micelios.}

La denominación de los basidiocarpos mayoritariamente utilizada en el territorio estudiado es naranjones que, a su vez, cuando están maduros, también son denominados gachetas. Solo de unos pocos informantes se han recogido otras dos denominaciones, güevos del juagarzo y pelotas de juagarzo, derivadas ambas de una de las formas habituales que suele presentar los basidiocarpos y de su asociación con la planta a la que se atribuye su origen. Finalmente, un solo informante los denominaba negrejones, relacionando el origen del nombre con el color negruzco de su exterior. Todas las muestras revisadas correspondieron a la especie $M$. variegatus.

A diferencia de lo recogido sobre el saber popular relativo a Terfezia (Cano, 2003), en este caso si hay un buen número de informantes que identifican claramente el micelio de $M$. variegatus, bien como una extensión de las raíces de Cistus clusii Dunal. en forma de "raicillas pequeñas" que, "si arrancas el juagarzo se quedan en el suelo" o bien como una especie de telarañas o "telico pajizo (como el que hacen las arañas)" subterráneo próximo a estas raíces. 
Al margen de las variaciones en algunas características de $M$. variegatus comentadas por los informantes y que son debidas a los diferentes factores bióticos y abióticos actuantes en el territorio, dentro del concepto mental de naranjones conocidos por ellos, se engloban, al menos, dos tipos de naranjones que podrían corresponder a otras especies de hongos hipogeos diferentes a $M$. variegatus y que presentan mayor o menor parecido morfológico con esta especie, compartiendo territorio, hábitat o plantas simbiontes con los naranjones habituales. En uno de los casos, se trataría de una especie simbionte con Cistus ladanifer L. ("los naranjones de la jara son más negros que los del juagarzo y más gordos y más dulces") y en otro caso sería una especie simbionte con Cistus albidus L. distinta del naranjón tipo también producido habitualmente por esta planta ("naranjones más gordos pero que se rompían fácilmente y eran más malos y se los comían las cabras").

\section{Plantas simbiontes}

La especie mayoritariamente citada por los informantes como productora de $M$. variegatus es
C. clusii. Se trata de una planta muy frecuente en la Región de Murcia que se extiende por la práctica totalidad del territorio que comprende, salvo en zonas de elevada altitud de su parte noroeste. En el territorio de recolección tradicional de $M$. variegatus en nuestra Región es frecuente y se conoce como juagarzo, (pronunciado tradicionalmente con seseo en algunas zonas de Cartagena) denominación popular que también se presenta en el interior, desde la comarca oriental llegando hasta Jumilla y hacia el interior del municipio de Lorca y parte del de Totana y Mula. Otras denominaciones usadas tradicionalmente para esta planta en otras áreas de la Región han sido quiebraollas, quebraollas, rompeollas, romero macho y, más raramente, romero borde, jabarzo y romero. Muy puntualmente también se ha recogido el nombre de juagarzo fino, utilizado, sobre todo, cuando se compara con alguna otra especie de su género de aspecto similar. En la zona litoral fue una planta muy empleada como leña ("es una leña buena para los hornos pero para cogerla es mala, te haces las manos mixtos, es muy bronca") y, esporádicamente, como medicinal u otros usos menores.

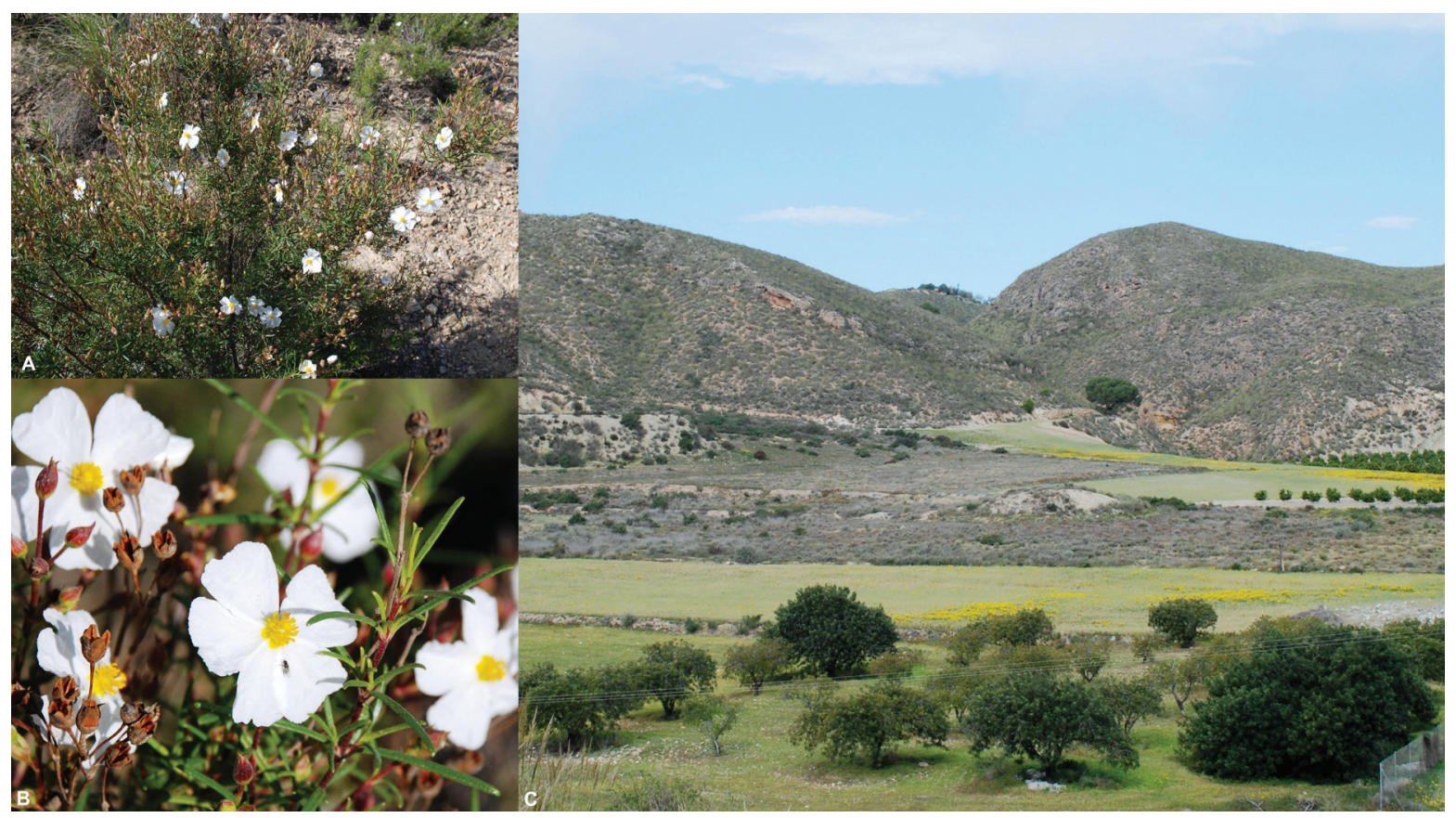

Figura 2. A) y B) C. clusii . C) Zona productora de M. variegatus. 
En menor medida que la anterior especie, se cita a $C$. albidus como planta productora de $M$. variegatus. Se trata también de una planta muy extendida en nuestra Región y presente en la zona de recolección tradicional de $M$. variegatus. El nombre popular mayoritariamente empleado en toda la Región es estepa. Muy esporádicamente he oído estrepa y, excepcionalmente, estopa y jara estepa. Su uso primordial fue servir de leña menuda $\mathrm{y}$, secundariamente, como sustituto del tabaco y planta medicinal.

Puntualmente, también se cita a C. ladanifer como productora de naranjones si bien, posiblemente, se trataría de otra especie distinta a $M$. variegatus sin descartar que también produzcan el naranjón tipo. Se trata de una especie muy escasa en nuestra Región y también en el territorio de recolección tradicional de $M$. variegatus aunque, no obstante, en él era una planta apreciada de la que se conocían con precisión los parajes donde habitaba, utilizándose para denominarla el nombre de jara, siendo empleada primordialmente como planta medicinal con diversos fines, apreciándose mucho para la curación de heridas externas en personas.

Todavía más puntualmente (sólo dos informantes y, uno de ellos, con dudas) citaron como productora de nuestro hongo a Cistus monspeliensis L., conocida como juagarzo basto o solo como juagarzo.

También se recogió alguna mención al romero, Rosmarinus officinalis L., como productora de $M$. variegatus, aunque se trataba de confusiones por su parecido con C. clussii cuando no está en floración o por hallarse esta especie mezclada en matorrales con especies productoras del hongo. Solo una persona, considerada como buen informante, no confundía las especies y mantenía su

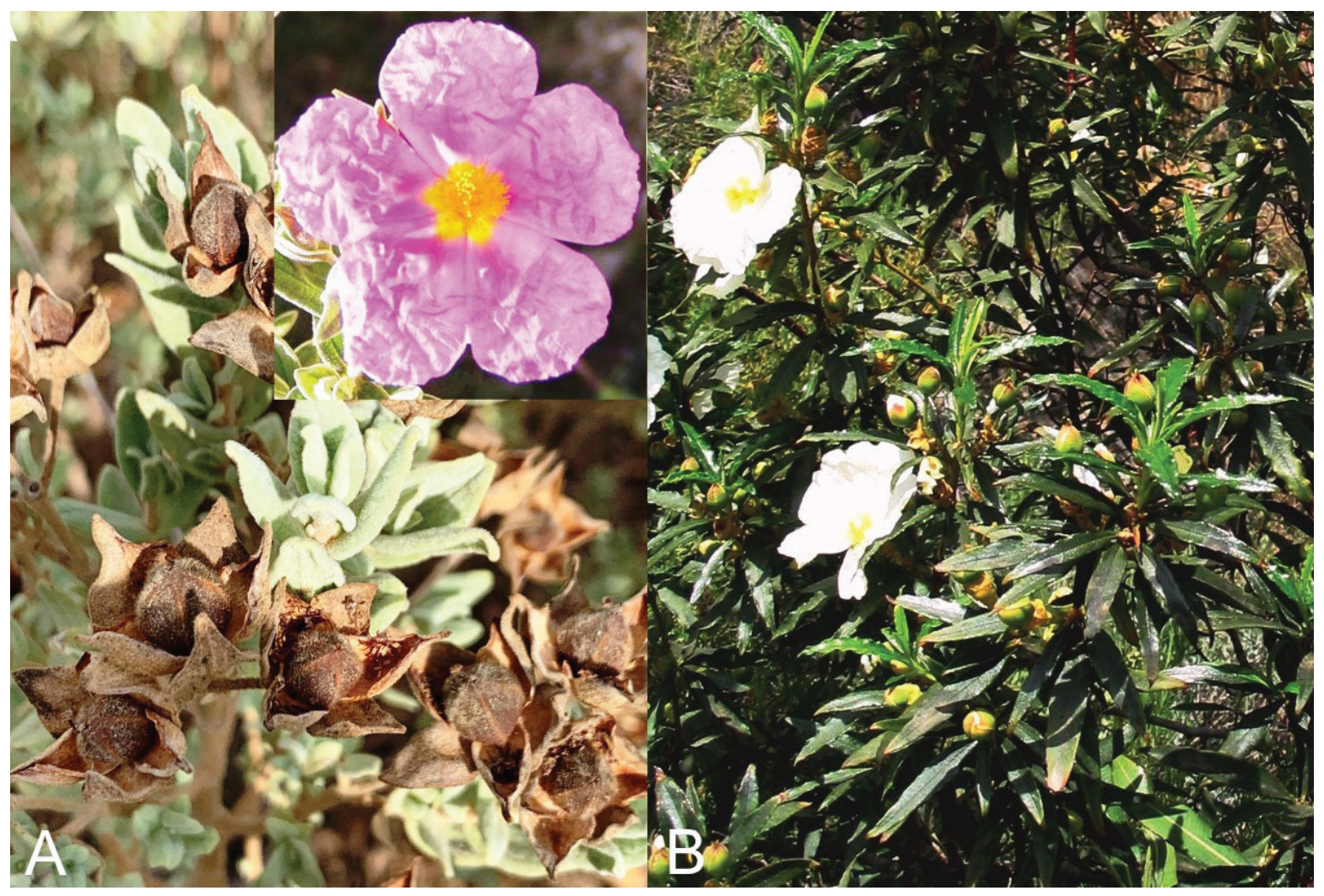

Figura 3. A) C. albidus B) C. ladanifer. 
afirmación con aparente credibilidad ("también hay güevos en algún romero: de cada cien, uno") si bien hay que poner en duda esta información a tenor de la ausencia de citas de simbiosis ectomicorrícicas en las plantas de la familia lamiaceas.

\section{Zonas tradicionales de recolección}

La zona tradicional de recolección de $M$. variegatus en la Región de Murcia se localiza dentro de los municipios de Águilas, Lorca, Totana, Mazarrón y Cartagena. Del conjunto de parajes o fincas donde los informantes lo han recolectado o visto hacerlo, derivan las cuadrículas UTM incluidas en la Figura 4 (solo se colorean las cuadrículas en la parte incluida en el ámbito territorial de la
Región de Murcia, realizándose su coloreado completo cuando, al menos en una zona incluida en la cuadrícula se haya constatado su recolección).

Como zonas tradicionales de recolección se recopiló de los informantes una amplia relación de parajes con vegetación espontánea localizados en áreas litorales y prelitorales de estos municipios, sobre todo en lomas, cabezos y sierras, dado que las zonas llanas están mayoritariamente ocupadas con cultivos. A lo largo de la investigación, estos informantes únicamente refirieron un microtopónimo referido a este producto, La Loma de los $\mathrm{Na}$ ranjones, paraje muy poblado de juagarzos y con alta productividad de $M$. variegatus.

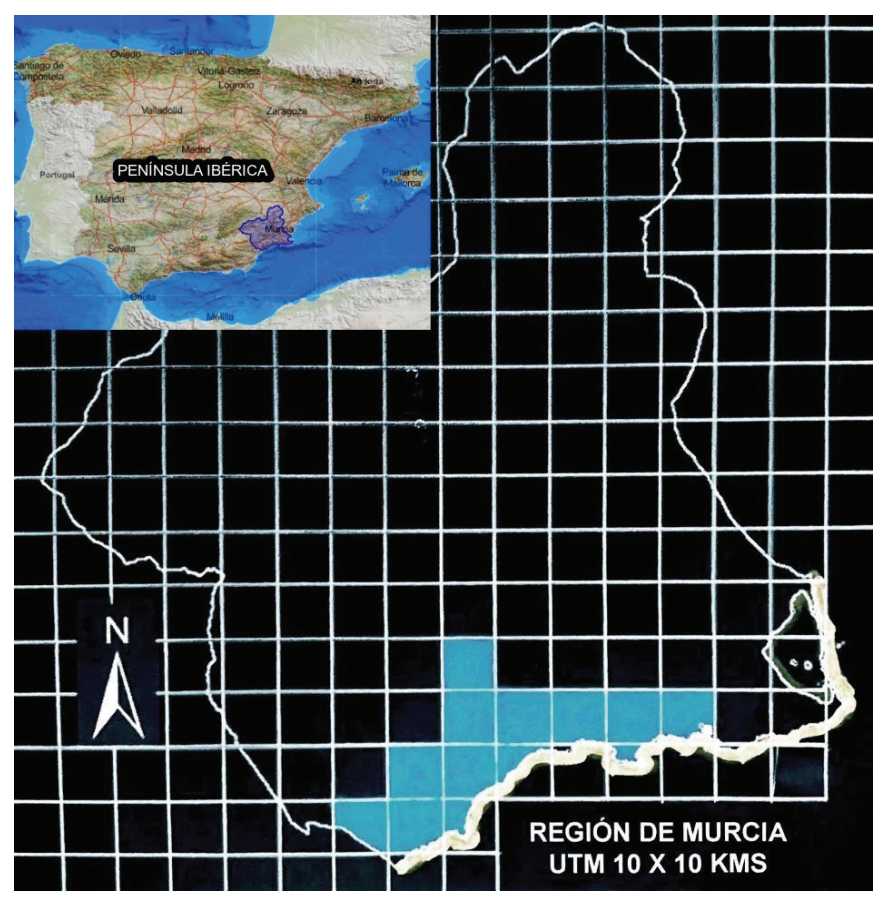

Figura 4. Mapa de recolección tradicional de M. variegatus en la Región de Murcia.

\section{Características de los hongos recolectados}

Los tamaños manifestados por los informantes respecto de los basidiocarpos recolectados, vistos o consumidos por ellos son variados. Estos van desde "la cabeza de una cerilla" hasta uno que "pesaba más de medio kilo". Los tamaños más habituales son ejemplares de 4 a $5 \mathrm{~cm}$, son escasos los de 6 a $7 \mathrm{~cm}$, muy escasos de 7 a $8 \mathrm{~cm}$ ("de cada cien, alguno hay") y excepcionales los que superan este tamaño.

Los informantes refieren como habitual color externo de los naranjones el amarillo dorado o marrón que luego se vuelve negruzco o negruzcorojizo con la madurez. Por dentro predomina el color blanco cuando son inmaduros que se transforma 
en negro al madurar, presentando una venosidad de color blanco ("va haciendo un chispao blanco", "parece un tejido"). En su última fase el contenido del naranjón, que ya es gacheta, "se hace líquido desde dentro hacía afuera", lo que permite su recolección sin que se produzca el vaciado al exterior del sabroso contenido licuado.

En cuanto a la forma habitual de los ejemplares observados, se destaca la predominancia de formas redondeadas u ovaladas, junto con formas más alargadas o irregulares sobre todo, en este último caso cuando, en su crecimiento, se encuentran algún obstáculo, generalmente una piedra, que actúa de barrera o condicionante para un desarrollo más libre y homogéneo.

El número de naranjones que, según los informantes, puede llegar a producir un mismo juagarzo es variable. Además, se indica que los naranjones recolectados pueden serlo en solitario o aparecer varios juntos (hasta en número de 6), muy próximos entre sí, siendo, en este caso, normalmente de un tamaño más pequeño.

\section{Origen}

Respecto a las informaciones aportadas por los entrevistados sobre el origen de los naranjones hay que señalar que existe una creencia mayoritaria de que éstos son una producción directa de los juagarzos o de las otras especies vegetales que los producen: "lo echan los juagarzos. Es una gracia que Dios les mandó". Muchos informantes hablan de una conexión física entre los naranjones y las raíces de las plantas simbiontes, bien directamente o a través de "raicillas pequeñas" o un "telico pajizo (como el que hacen las arañas)". Además, se comenta que, habitualmente, "se fraguan" u originan muy cerca de la superficie, raramente a cierta profundidad. No se ha recogido ninguna creencia relativa a que deriven de enfermedades de las plantas simbiontes o a algún tipo de causa mágica o no convencional. Solo alguno de los informantes, apoyándose en la débil conexión física entre el hongo y las raíces de la planta, afirma que no son una producción directa de la planta aunque, no obstante, sí se apunta como necesario que existan éstas en una zona determinada para que en ella puedan originarse. Como sucede con el resto de hongos hipogeos de nuestra Región conocidos popularmente, los naranjones no son emparentados etnotaxonómicamente con las setas u hongos de superficie.

\section{Épocas de recolección y perfil de los recolectores}

Si se dan las condiciones adecuadas para ello, la época de recolección más habitual de los naranjones es primavera, sobre todo los meses de marzo y abril, teniéndose como fechas señaladas de recolección las coincidentes con la celebración de la Semana Santa. No obstante y de forma puntual, en condiciones climáticas favorables para ello, se indican enero y mayo como meses extremos en los que se han recolectado en nuestra zona.

Se trataba de un producto consumido periódicamente por amplias capas de la población de las zonas prospectadas aunque la recolección era más frecuente en algunos sectores de la misma, como en aquellas profesiones relacionadas con el monte, como pastores o leñadores. Se ha recogido también que la recolección de este producto "estaba libre", es decir, no se ponían impedimentos legales para realizarla, incluso en propiedades privadas. También era tradicional y habitual que grupos de jóvenes salieran específicamente a la búsqueda de este producto con un componente fundamentalmente lúdico, sobre todo en Jueves Santo y Viernes Santo y, hablar de ello, después de tantos años, todavía supone para estos críos de antaño y ancianos hoy, un grato y muy especial recuerdo.

Los recolectores habituales de naranjones no solían serlo también de turmas, tanto por la menor presencia de este otro recurso micológico en las zonas de recolección tradicional del primero y, probablemente también, por constituirse éste en foco de atención prioritaria en el esfuerzo recolector de sus habitantes. 
Ya a finales del siglo XX y comienzos del siglo XXI la recolección de naranjones es muy escasa si la comparamos con épocas anteriores. Los pocos que todavía los recolectan corresponden, sobre todo, a algunas personas de mediana o avanzada edad que realizan alguna actividad en el medio natural o alguna persona que esporádicamente quiere rememorar gratas experiencias pasadas y todavía se encuentra en condiciones físicas para hacerlo.

\section{Indicios para su recolección}

Fruto de la observación popular a lo largo de los años, tanto a nivel individual como colectivo, se van generando una serie de señales o indicios que nos proporcionan información sobre producciones del medio silvestre u otros acontecimientos relacionados con el mismo. Así, en relación con la producción de naranjones, además de las precipitaciones y temperatura, se han recogido otras señales precisas asociadas a la aparición de este producto, algunas de las cuales evidencian un buen conocimiento de su ciclo biológico.

Una de estas señales es el estado del micelio productor de los naranjones, un hecho que se estima como singular dentro del acervo etnomicológico en la Península Ibérica. Se trataba de hacer un seguimiento del micelio en aquellas épocas donde podría originar basidiocarpos, el cual podía realizar mediante una revisión visual, mediante el olfato o de ambas formas: "antes de que haya naranjones levantas una piedra y ves el telo", "la muestra del naranjón es como una tarataña amarilla pegada a las raíces. De chicos arrancábamos las raíces para ver si tenían muestra, y también olíamos las raíces a ver si echaban olor a naranjones".

Otras señales propicias son una abundante floración y emisión de brotes por los juagarzos, concentrándose la prospección sobre aquellos ejemplares con mayor vitalidad ("siempre se le tira al más grande o al que ha talleao más"), señales que se producen en años con un régimen climatológico favorable. Algún informante también refiere como señal favorable para la producción de naranjones la presencia de tinajas o tenajas (Cytinus hypocistis (L.) L.) en el juagarzo, (se trata de una planta que crece de forma parásita sobre el mismo).

\section{Métodos de recolección}

El método más habitual de localización y recolección de los naranjones ha sido la observación del terreno alrededor de las plantas simbiontes (no en la zona inmediatamente pegada al tronco principal) para descubrir la elevación existente en el mismo (llamada habitualmente bufeta o burbujón) a consecuencia del crecimiento del hongo, que produce generalmente un resquebrajamiento de la tierra ("la tierra la esponjan y se raja") permitiendo su exacta localización para, después, proceder a excavar con las manos o con algún instrumento hasta dar con él o ellos. Sin embargo, los naranjones pequeños no producen ese efecto en el terreno ni tampoco los situados debajo de piedras superficiales de cierto tamaño, donde es frecuente que se sitúen por la mayor humedad que conserva el suelo bajo las mismas. Se comenta también por parte de los informantes que, habitualmente, la producción se concentraba más en unas zonas determinadas respecto de otras formando manchas o roales de naranjones, bien conocidos por algunos recolectores.

Otra forma tradicional de recolección iba asociada generalmente a la extracción de leña de juagarzo o, en menor medida, de estepa, tratándose nuestro hongo, en este caso, de un aprovechamiento secundario. El arranque del juagarzo con el fin exclusivo de recolectar el hongo ha sido más raro y no practicado generalmente por los recolectores tradicionales: "la gente del campo no arranca los juagarzos", "la gente que no sabe buscar arranca el juagarzo". Se trata éste de un método menos selectivo y eficaz que supone un menor porcentaje de éxito en la recolección (los basidiocarpos normalmente no salen pegados a las raíces de la planta) y un mayor esfuerzo en la misma al tener que buscar en la tierra removida a consecuencia del arranque de la planta. 
En cuanto al efecto sobre la producción de naranjones del arranque selectivo de las plantas simbiontes, hay quien ve en ello consecuencias negativas para futuras cosechas de los mismos al desaparecer el soporte que los origina mientras que, otros, piensan más en el efecto de este arranque sobre el monte en su globalidad que se considera positivo al favorecer la fertilidad del suelo, el crecimiento de pequeñas plantas y la renovación de la comunidad vegetal: "arrancar las matas del juagarzo es bueno, se hace barbecho".

\section{Factores relacionados con su producción}

Suelos:

El tipo de suelo o tierra es un factor considerado por los informantes como importante en la producción y calidad de los naranjones. Dotado cada suelo de unas características particulares, influye tanto sobre el micelio y desarrollo del basidiocarpo, como, indirectamente, a través de sus repercusiones sobre las plantas simbiontes, condicionando las cualidades organolépticas de nuestro hongo, su tamaño, forma, productividad, accesibilidad etc. Las "tierras colorás" y las "tierras negras" se citan como buenas productoras ("los naranjones están más dulces") mientras que las azules producen naranjones de peor calidad ("están más esabrios”, "cuando los abres están más blanquijos") y las "tierras blancas" no los producen.

Entre esas características del suelo que afecta a la producción de naranjones se cita su profundidad ("siendo un terreno con más molla, mejor"), porosidad ("donde hay tierra esponjá mejor", "la tierra colorá es la mejor, es más floja y le cuesta menos trabajar"), textura ("en las tierras sueltas los naranjones que hay son más gordos"), materia orgánica ("cuanto más basura de hojas tiene la tierra es donde más naranjones hay"), pedregosidad ("hay muchos debajo de las piedras") etc. Estas características se ven directamente condicionadas por las prácticas culturales de aprovechamiento o manejo de la vegetación de las zonas productoras.
Topografía:

Son escasos los datos recabados sobre la influencia de la topografía del terreno en la producción de naranjones siendo, sobre todo, factores que guardan relación con la humedad del terreno y la insolación. Mientras hay quien manifiesta que sólo ha encontrado naranjones en situaciones de "cara al sol" o "cara al mar", algún otro informante señala que los ha encontrado, aparte de en la exposición anterior, también en la "cara al norte" o "cara de la umbría". Por otro lado, también se afirma que, donde el juagarzo se beneficia de más humedad, aumenta la producción del hongo y, por ello, se citan las vaguadas y hondonás como situaciones topográficas favorables para la producción de naranjones.

\section{Climatología:}

La pluviometría se considera por los informantes como un factor esencial para la producción de naranjones por cuanto condiciona que los mismos se puedan, o no, originar, en qué número lo hagan y qué tamaño alcancen. Se apunta que afecta tanto la cantidad de lluvia caída como las épocas en las que se produzca: "tiene que llover en su tiempo para que sea un buen año de naranjones". Si las lluvias se producen de forma suficiente en otoño o invierno las plantas simbiontes y el micelio adquieren el estado vegetativo adecuado para la posterior producción de naranjones, aunque ésta sólo se producirá si tiene lugar algún episodio de lluvia en cantidad suficiente dentro de la época de recolección: "tiene que ser un año que llueva en su tiempo debio para que el juagarzo se retoñe y tire (en invierno, y luego en primavera otra vez)", alcanzando un tamaño adecuado para su recolección entre los 4 a 7 días tras las lluvia., "si llueve, en 4 o 5 días salen (las raíces están en savia, están buenas)".

Por el contrario, una vez los naranjones ya están bien desarrollados, la lluvia provoca que se estropeen y no puedan ser consumidos: "el naranjón le parece a los higos verdales: si están madu- 
ros y les cae agua ya no valen (se abren y se agusanan)". Un informante comentó como curiosidad el caso de un juagarzo que, por estar junto a una fuente, recibía riego complementario al agua de lluvia y ello tenía como consecuencia que produjera naranjones de forma más constante y frecuente que los juagarzos del entorno.

Además, a juicio de los informantes, la temperatura es un factor importante para que se originen naranjones, siendo favorables las temperaturas cálidas y desfavorable un frío o calor excesivo: " $\mathrm{el}$ frío no les va", "este año la cosecha viene tarde por lo bajo de las temperaturas", "puede haber en mayo, antes de que apriete el sol".

Componente vegetal:

Algún informante considera que los juagarzos de pequeña altura (no se refiere a plantas muy jóvenes) y edad algo avanzada son buenos productores de naranjones. Descartando los ejemplares muy envejecidos, hay quien considera que los ejemplares que son más grandes y tienen vitalidad o buena salud son los que presentan una mejor productividad de este producto.

Por otro lado, para algunas de las personas entrevistadas, la presencia en el monte de juagarzos intercalados con otras especies vegetales es positivo para la producción de naranjones, no siéndolo la presencia de formaciones monoespecíficas de esta planta: "no hay muchos naranjones donde se ven muchos juagarzos (es mejor que estén mezclados con otras plantas)".

También se recogió la creencia de que el espesamiento del monte a consecuencia del abandono de los aprovechamientos tradicionales efectuados sobre el mismo perjudica la producción de naranjones. Con mayor fuerza, todavía, esta creencia también ha existido respecto a la producción de hongos hipogeos del género Terfezia en la Región de Murcia (Cano, 2003) aunque, en este otro caso, el perjuicio puede ser mayor pues, además de la menor insolación y cambio de las características del suelo, por su pequeño tamaño, puede hasta peligrar la propia presencia de las plantas simbiontes (pertenecientes al género Helianthemum).

Una única persona (considerada buen informante), también cita la presencia concreta del romero (Rosmarinus officinalis L.) en zonas ocupadas por juagarzo como factor potenciador de la producción de naranjones por los mismos (aunque, a este respecto, también podría suceder que, cuando hay juagarzos con alta productividad de naranjones se favorece el asentamiento de romero junto a ellos).

\section{Usos como comestible u otros usos humanos}

Los naranjones han sido tradicionalmente muy apreciados en la zona como alimento de capricho, consumidos siempre crudos, ("era un bocao exquisito") y, más aun, las gachetas, es decir, naranjones con su contenido licuado (no podrido) a modo de leche condensada, que se consideran un manjar. Más raramente, algunas personas los utilizaban picados como condimento de algunas comidas (por ejemplo, algunos guisos y arroces) a las que transmitía su agradable y característico sabor, siendo una práctica asociada a "gente antigua", practicante de costumbres de épocas pasadas.

Antes de ser ingeridos, se limpian o lavan con agua. Lo habitual ha sido comérselos con piel incluida. Podían guardarse en casa durante varios días antes de ser consumidos. Las gachetas se abrían con cuidado para que no se vaciara su líquido interior que es lo que se consume de los naranjones maduros.

Su sabor se describe habitualmente como parecido al regaliz y hay quien también señala que "sabe a las cosas del monte", destacándose siempre su gran dulzor. Este sabor va a sufrir pequeñas variaciones en función de diversos factores rela- 
Tabla 2. Tipología y frecuencia de factores bióticos o abióticos citados por los informantes en relación con su influencia en la producción de basidiocarpos de $M$. variegatus en la zona estudiada.

\begin{tabular}{|c|c|c|c|}
\hline \multicolumn{2}{|r|}{ FACTOR } & FAVORABLE & DESFAVORABLE \\
\hline \multirow{4}{*}{ 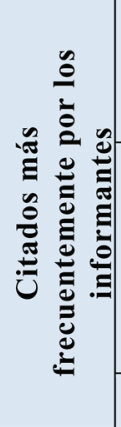 } & $\begin{array}{l}\text { PRESENCIA DE } \\
\text { PLANTAS } \\
\text { SIMBIONTES }\end{array}$ & $\begin{array}{c}\text { Jaguarzos } \\
\text { Estepas } \\
\text { Otras matas }\end{array}$ & \\
\hline & \multirow{2}{*}{$\begin{array}{l}\text { PLUVIOMETRÍA / } \\
\text { HUMEDAD EN EL } \\
\text { SUELO }\end{array}$} & \multirow{2}{*}{$\begin{array}{l}\text { Lluvia abundante en } \\
\text { otoño/invierno y } \\
\text { puntual en la época de } \\
\text { recolección }\end{array}$} & $\begin{array}{l}\text { Lluvia ausente o } \\
\text { insuficiente }\end{array}$ \\
\hline & & & $\begin{array}{l}\text { Lluvia una vez } \\
\text { crecidos los } \\
\text { basidiocarpos }\end{array}$ \\
\hline & TEMPERATURA & Media & Bajas y altas \\
\hline \multirow{11}{*}{ 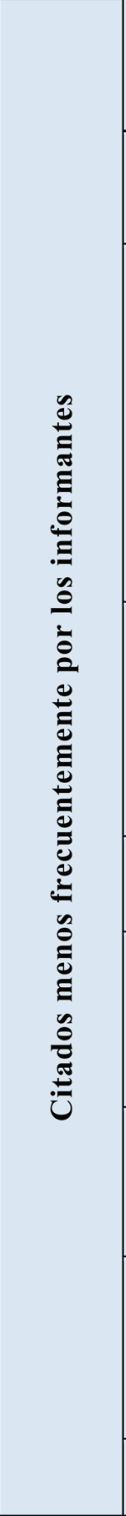 } & $\begin{array}{l}\text { EDAD DE LAS } \\
\text { PLANTAS } \\
\text { SIMBIONTES }\end{array}$ & $\begin{array}{l}\text { Ejemplares de edad } \\
\text { adulta }\end{array}$ & $\begin{array}{c}\text { Ejemplares muy } \\
\text { jóvenes o } \\
\text { envejecidos }\end{array}$ \\
\hline & $\begin{array}{l}\text { VIGOR DE LAS } \\
\text { PLANTAS } \\
\text { SIMBIONTES } \\
\end{array}$ & Ejemplares vigorosos & $\begin{array}{l}\text { Ejemplares poco } \\
\text { vigorosos }\end{array}$ \\
\hline & \multirow[b]{2}{*}{ TOPOGRAFÍA } & $\begin{array}{l}\text { Orientación del terreno } \\
\text { en solana, } \\
\text { (Orientación de umbría) }\end{array}$ & \multirow{2}{*}{$\begin{array}{c}\text { Situaciones } \\
\text { topográficas } \\
\text { desfavorables para el } \\
\text { mantenimiento de la } \\
\text { humedad en el suelo }\end{array}$} \\
\hline & & $\begin{array}{c}\text { Situaciones } \\
\text { topográficas que } \\
\text { favorezcan el } \\
\text { mantenimiento de la } \\
\text { humedad en el suelo }\end{array}$ & \\
\hline & \multirow{2}{*}{$\begin{array}{l}\text { COMPOSICIÓN } \\
\text { FLORÍSTICA }\end{array}$} & $\begin{array}{c}\text { Matorrales con mezcla } \\
\text { de } C \text {. clusii con otras } \\
\text { especies vegetales }\end{array}$ & \multirow{2}{*}{$\begin{array}{c}\text { Matorrales } \\
\text { monoespecíficos de } \\
\text { C. clusii }\end{array}$} \\
\hline & & $\begin{array}{c}\text { Mezcla de } C \text {. clusii con } \\
\text { Rosmarinus offinalis }\end{array}$ & \\
\hline & $\begin{array}{l}\text { ESTRUCTURA DE LA } \\
\text { VEGETACIÓN }\end{array}$ & $\begin{array}{c}\text { Matorrales poco } \\
\text { espesos }\end{array}$ & $\begin{array}{c}\text { Matorrales muy } \\
\text { espesos }\end{array}$ \\
\hline & $\begin{array}{l}\text { APROVECHAMIENTOS } \\
\text { TRADICIONALES DEL } \\
\text { MONTE (extracción de } \\
\text { leña, pastoreo...) }\end{array}$ & $\begin{array}{l}\text { Realización de } \\
\text { aprovechamientos } \\
\text { múltiples de forma } \\
\text { racional }\end{array}$ & Abandono \\
\hline & TIPO DE SUELO & $\begin{array}{l}\text { Tierras rojas } \\
\text { T. negras } \\
\text { T. azules }\end{array}$ & Tierras blancas \\
\hline & TEXTURA DEL SUELO & $\begin{array}{c}\text { Tierras sueltas } \\
\text { Aireación de la tierra } \\
\text { por acción humana o } \\
\text { animal }\end{array}$ & Tierras compactas \\
\hline & $\begin{array}{l}\text { INSOLACIÓN SOBRE } \\
\text { EL SUELO }\end{array}$ & Alta & Baja \\
\hline
\end{tabular}


cionados tanto con el medio abiótico donde se produzcan como con la planta simbionte con la que se asocie. En relación con este último factor se señala, por ejemplo, que los naranjones de las estepas están menos dulces que los de los juagarzos.

\section{Fauna consumidora}

En relación con la fauna consumidora de los naranjones, se ha recogido de los informantes la mención de diferentes animales que se alimentan de forma habitual de este hongo en la zona de estudio. Como mamíferos, se mencionan los jabalises (Sus scrofa L.), tajones o tejones (Meles meles L.) y los conejos (Oryctolagus cuniculus L.). Dentro de las aves, son muy nombradas las tutuvías o tutovías (Galerida cristata L., Galerida theklae A. E. Brehm), que se muestran muy activas escarbando con su pico para desenterrar el hongo y, en menor medida, las perdices (Alectoris rufa L.). También son citados los lagartos (Lacerta lepida Daudin) y, sobre algunos ejemplares muy maduros o podridos por la lluvia, los gusanos.

\section{DISCUSIÓN Y CONCLUSIONES}

M. variegatus es una especie ampliamente distribuida a nivel mundial y bien conocida en el ámbito científico pero, son muy pocas las referencias relativas a su conocimiento o aprovechamiento popular constituyendo el presente trabajo, hasta el momento, una de esas escasas excepciones. Por ello, serían deseables futuras investigaciones destinadas a averiguar si el conocimiento y aprovechamiento popular de este recurso también se encontraba o encuentra presente en otros territorios donde habita este hongo.

Este trabajo contiene un variado repertorio de conocimientos o saberes populares sobre esta especie en el ámbito territorial de la Región de Murcia y que forman parte de su patrimonio cultural inmaterial. Así, se han recogido datos relacionados con sus características, plantas simbiontes, métodos de extracción, zonas de recolección tradicional, origen, consumo y otros diversos aspectos.

La constatación de la ausencia de aprovechamiento popular en otras zonas de la Región de Murcia, mediante realización de encuestas, no implica que esta especie no haya estado o esté presente en esas zonas distintas de las correspondientes a su área de recolección tradicional. Ejemplo de esto es la cita pionera referida a su presencia en las proximidades del Pantano de Puentes, en el interior del municipio de Lorca (Honrubia, Cano \& Molina, 1992).

Sin embargo, la no localización de citas bibliográficas o documentales (o el indicio que puede representar de que, en el caso de haberlas, serían escasas) supone un hecho diferencial respecto a lo sucedido en la investigación anterior sobre el género Terfezia llevada a cabo en nuestra Región (Cano, 2003), y podría deberse a la más restringida distribución de su conocimiento y aprovechamiento, su menor contribución como alimento de subsistencia para la población, que limita su reflejo en la documentación antigua o, quizás, a que pueda tratarse de un aprovechamiento de menor antigüedad histórica.

Son conocimientos de especial interés, aquellos concernientes a los factores que, a nivel popular, se consideran que influyen en la producción de los basidiocarpos, así como la constatación de los beneficios del arranque moderado de determinadas especies arbustivas en la productividad y diversidad vegetal y las consecuencias positivas de dicha diversidad. Además de su utilidad para la gestión moderna de nuestro medio natural, este tipo de conocimientos tradicionales pueden servir de apoyo o complemento a la investigación científica convencional constituyendo material de partida para que futuros investigadores los analicen científicamente o para proporcionar ideas con las que emprender proyectos de investigación básica o aplicada. 
Por otra parte, dadas las cualidades gastronómicas del hongo, podría ser oportuno, al igual que se ha llevado a cabo en las últimas décadas con el género Tuber (truficultura) o Terfezia (turmicultura), desarrollar experimentaciones dirigidas a la producción agrícola controlada de $M$. variegatus (¿naranjonicultura?) que permita su explotación comercial sirviendo de apoyo al desarrollo endógeno de nuestras zonas rurales costeras, deseo que también comentó espontáneamente una de las personas entrevistadas.

Es sorprendente la profundidad en el conocimiento de su medio natural que todavía puede recopilarse de la población de un territorio, como en el que circunscribe la investigación llevada a cabo, perteneciente a la avanzada Unión Europea. A través de esta pequeña muestra de saber popular recogida en el presente artículo, se pone de manifiesto la gran capacidad de observación de un grupo diverso de personas ejercientes de actividades tradicionales en su medio natural.

Pero estos saberes constituyen un valioso patrimonio en vías de desaparición o que ya ha desaparecido total o parcialmente con el fallecimiento de personas de edad avanzada que vivieron en unas condiciones muy diferentes a las actuales y que participaron en su creación o mantenimiento, aportando una mayor o menor contribución individual. Además, no se trata solo de la pérdida de un conocimiento acumulado sino que, en gran medida, se han perdido los mecanismos de trasmisión intergeneracional que operaban en el pasado así como de observación del medio natural a consecuencia de su íntimo contacto con el mismo. Por otro lado, en la actualidad, han dejado de efectuarse la mayor parte de los aprovechamientos tradicionales ejercidos anteriormente sobre nuestros montes, los cuales, practicados de forma racional, contribuían a dotarlo de una alta biodiversidad y productividad. Por tanto, para conservar esta biodiversidad, necesitamos conocer estas prácticas culturales sobre el medio natural y las interacciones que se producen (Berkes \& Davidson-Hunt, 2006).

En lo referente a $M$. variegatus, el abandono de su recolección tiene como causas el fenómeno de la despoblación de las zonas con mayor grado de ruralidad, un menor aprovechamiento de los recursos del monte y la desconexión cultural de las nuevas generaciones con su medio natural más cercano, además de que puedan haberse sucedido, en el periodo comprendido durante el desarrollo del presente estudio, muchos años con un régimen pluviométrico desfavorable. En la actualidad y, sobre todo, de cara a un previsible incremento de la recolección de hongos hipogeos en la Región de Murcia, proveniente primordialmente de nuevos aficionados de zonas urbanas o con fines comerciales, quizás sea inevitable la implementación por las autoridades ambientales regionales de un marco regulatorio general de este recurso. Así ha sucedido modernamente en algunas regiones españolas como la Comunidad Autónoma de Castilla y León (Consejería de Economía y Hacienda, 2017), donde la regulación fue precedida de un estudio previo profundo de la realidad del recurso (Martínez, Oria \& Ágreda, 2011) y se intenta respetar los derechos e intereses vecinales, o en la Comunidad Autónoma de Madrid, donde se permite "la recogida consuetudinaria de leñas, frutos, plantas, setas o residuos forestales en los montes públicos" (Cuesta, 2012).

En la Región de Murcia, con una intensidad micológica recolectora actual menor que en Castilla y León, salvo en ciertos municipios y muy centrada actualmente en el género Lactarius, la realidad regulatoria es diferente. Solo las especies del género Terfezia son, teóricamente, objeto de regulación pública considerándolas en el desafortunado Decreto 50/2003 de creación del Catálogo Regional de Flora silvestre protegida de la Región de Murcia (Consejería de Agricultura, Agua y Medio Ambiente, 2003), como especies cuyo aprove- 
chamiento requiere, ¡nada menos!, que una autorización administrativa previa.

Sin embargo, el problema actual de la mayor parte de nuestros montes y de su flora (aparte de la transformación de usos del suelo o problemas globales como el cambio climático) no es su sobreexplotación sino el abandono de los aprovechamientos tradicionales sobre los mismos (en su mayor parte sostenibles e, incluso, recomendables para la salud y biodiversidad de nuestros montes humanizados). Sumado a esto, normativa como la que representa este Decreto, de corte academicista y prohibicionista, no fomenta precisamente su recuperación sino todo lo contrario. En una línea opuesta a la filosofía del mismo y fruto de su experiencia, Jesús Casas, ingeniero de montes de larga trayectoria como directivo de la administración forestal española, manifiesta que es necesario "desburocratizar, amortizar procedimientos y, probablemente, obviar la autorización por la regulación y perder esa capacidad de inmiscuirnos en todos y en cada uno de los actos y las actividades" (Casas, 2013).

Partiendo de las evidencias sobre el gran alcance y profundización que pueden tener estos saberes populares, se puede inferir la conveniencia de posibilitar o potenciar la capacidad de observación de su entorno natural más cercano de las generaciones más jóvenes, bastante desconectadas en la actualidad del mismo, así como lo oportuno de favorecer espacios o mecanismos de transmisión intergeneracional de la experiencia acumulada.

Además, con vistas a prestigiar y facilitar la transmisión moderna de los saberes populares en este campo, se precisa la existencia de una publicación divulgativa sobre las setas y hongos más frecuentes de nuestra Región, que recoja datos etnomicológicos (denominaciones populares en el territorio, zonas productoras, plantas o ambientes asociados, usos, gastronomía, métodos de recolección, manejo del medio natural, referencias históri- cas, creencias...) acompañados de imágenes, datos científicos y apreciaciones técnicas.

Estos saberes tradicionales resultantes del contacto intenso con su medio de generaciones de hombres y mujeres, también pueden servir como fuente de aprendizaje para el avance del conocimiento científico convencional y para la implantación de políticas de ordenación de actuaciones en el medio natural que tengan en cuenta la gestión tradicional por sus habitantes, sin imposiciones externas ajenas no consensuadas con los mismos, más propias de épocas pasadas. No obstante, la gran uniformización cultural producida en nuestro país en las últimas décadas y la tardanza de la comunidad científica y técnica en reconocer el valor de estos saberes tradicionales, menospreciados o ignorados generalmente por ésta, ha propiciado la pérdida definitiva de mucha información valiosa para la gestión actual del medio natural, de manera que parece que ya llegamos bastante tarde para emprender esta labor pendiente que, en nuestro territorio, a muy pocos les ha preocupado ni ocupado.

\section{AGRADECIMIENTOS}

Quede aquí reflejado mi sincero agradecimiento a todas las personas que, con mayor o menor grado de aportaciones, han hecho posible el presente trabajo. Tan sólo con algo de amabilidad e interés por sus vivencias y saberes, me ofrecieron desinteresadamente valiosos conocimientos, algunos de los cuales, a un paso de desaparecer para siempre. Personas como Antonio Liarte, Francisco Campos, Juan Sánchez, Pedro Martínez, Lorenzo Sánchez, Joaquín Guirao, Francisco Fuentes, Gabriel Madrid, Joaquín Torres, Pedro Vera, Pedro Gabarrón, Antonio Gallego, Lucía Ortíz, Cayetano Mateo, Pedro Méndez, Pedro López, Blas Hernández y su mujer Josefa, Diego Méndez, Catalina Sánchez, Angel Morales, Antonio Morales, Clemente Ortuño, Juana Navarro, Juan Navarro, Leonor Díaz y otros tantos de los que no recogí su 
Estudio etnomicológico de Melanogaster variegatus (Vittad.) Tul. \& C. Tul. - Cano F.

nombre, o sólo pude recoger su nombre sin apellidos o su mote (apodo). Gracias también a Lucía, mi mujer, por acompañarme en alguna de las salidas efectuadas con motivo de este trabajo y por su comprensión por el tiempo restado a otros menesteres para desarrollar esta particular afición mía por la investigación relacionada con temáticas un tanto atípicas. Muchas gracias a todos.
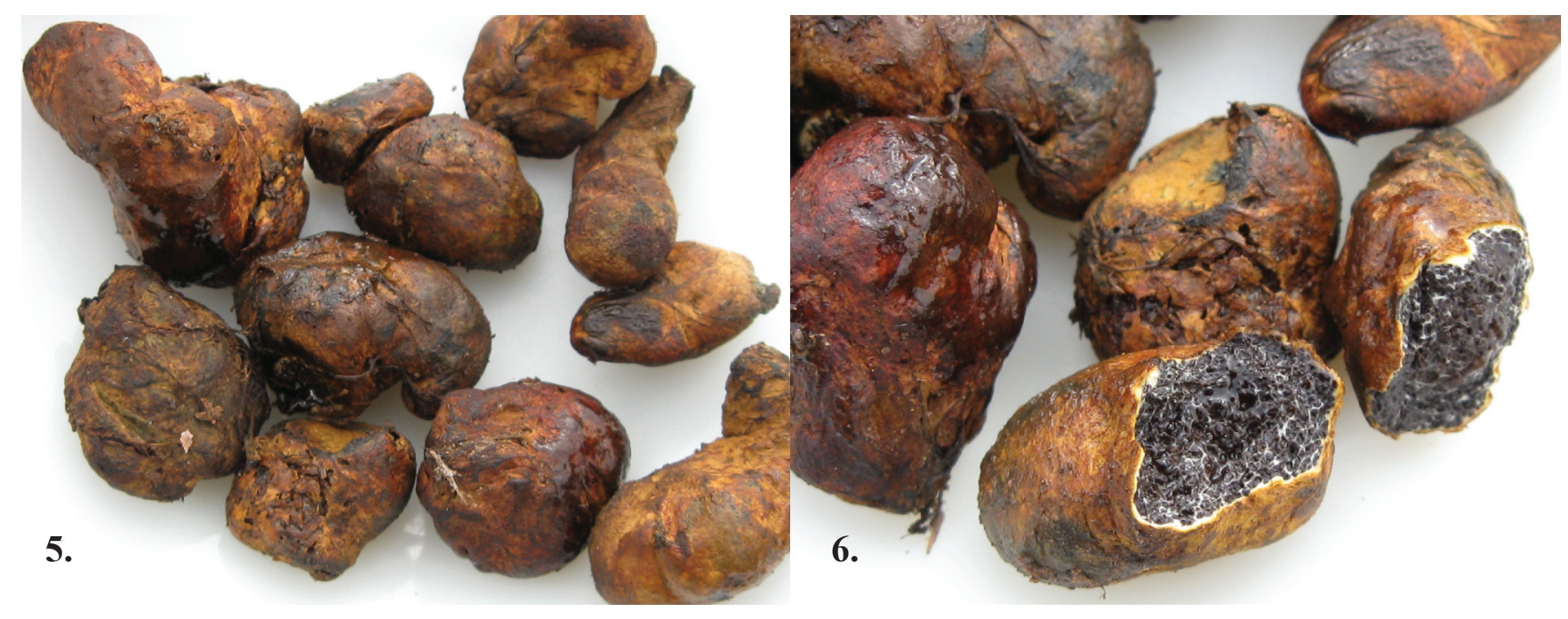

Figuras 5 y 6. $M$. variegatus.
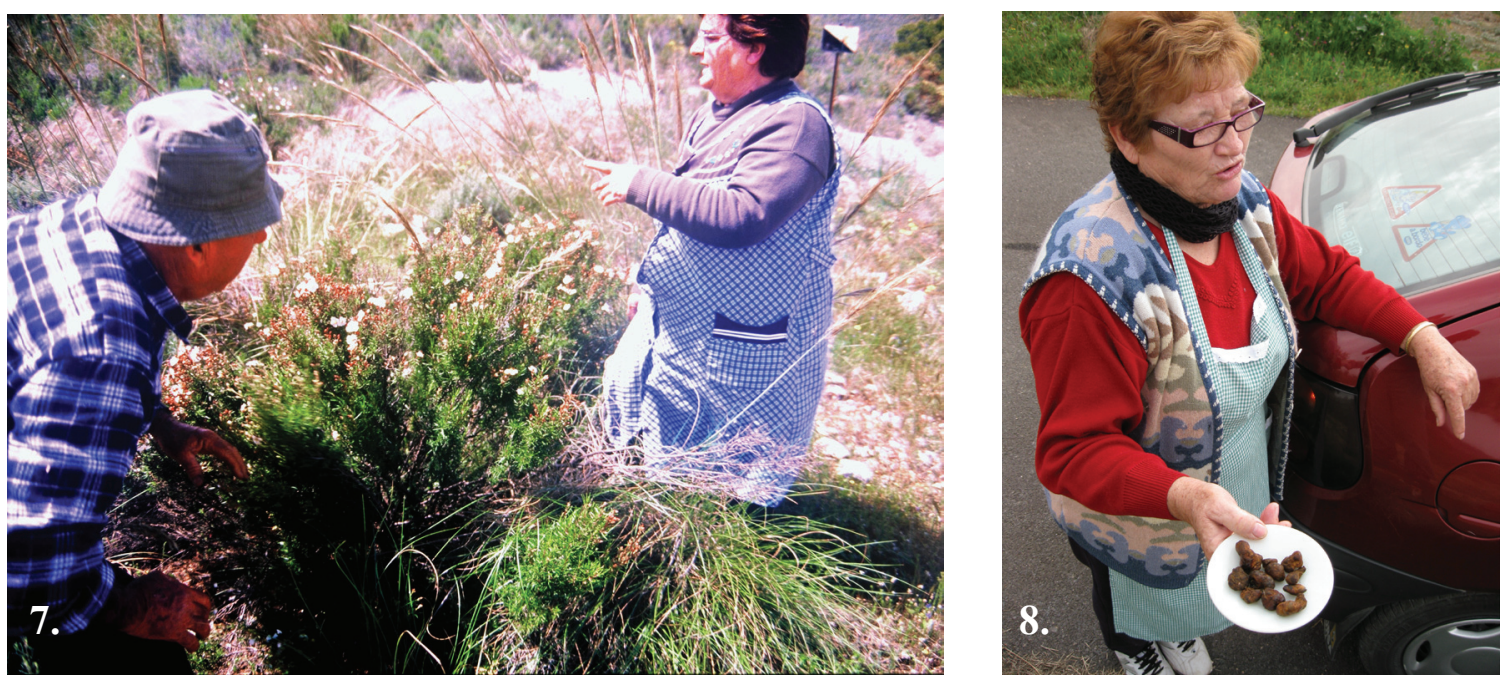

Figura 7. Recolectando M. variegatus.

Figura 8. $M$. variegatus. 


\section{REFERENCIAS}

Alcaraz, F., Barreña, J.A., Clemente, M., González, A.J., López, J., Rivera, D. et al. (2008). Manual de interpretación de los hábitats naturales y seminaturales de la Región de Murcia. Tomo 1. Consejería de Desarrollo Sostenible y Ordenación del Territorio. Comunidad Autónoma de la Región de Murcia. Murcia. 180 pp.

Aldama, J.A. Setas de Vizcaya. En Mushrooms Guide [Internet]. [consultado en 2018, septiembre] Disponible en: https://www.instagram.com/p/Bg9 m3PpgNqv/?tagged=setasdevizcaya.

Barceló, F. (1871-81). Flora de las Islas Baleares. Estab. Tip. de Pedro José Gelabert. Palma. 645 pp.

Barriuso, J.J. (2011). Inventario de los hongos micorrícicos competidores y contaminantes de las plantaciones de trufa negra en las comarcas productoras turolenses. Evolución del estatus micorrícico de las truferas en función de actuaciones externas (informe). Centro de Investigación y Tecnología Agroalimentaria de Aragón. Gobierno de Aragón. 30 pp.

Berkes, F. y Davidson-Hunt, I.J. (2006). Biodiversity, traditional management systems, and cultural landscapes: examples from the boreal forest of Canada. International Social Science Journal, 58 (187): 35-45.

Bregon, F. (2013). Catalogación de la flora micológica en el monte Los Frailes (informe). Centro de Estudios Micológicos T. Mariano Losa. 8 pp.

Boscà y Casesnoves, E. (1873). Memoria sobre hongos comestibles y venenosos de la provincia de Valencia. Imp. Ferrer de Orga. Valencia. 645 pp.

Broome, C.E. (1871). Remarks on some of the fungi met with in the neighbourhood of Bath. Proceedings of the Bath Natural History and Antiquarian Field Club, 2: 188-203.
Cabero, J. y Calzada, A. (2014). Catálogo provisional de hongos hipogeos de la provincia de Zamora. Boletín de la Asociación Micológica Zamorana, 15: 8-52.

Calonge, F.D. (1973). Estudios sobre hongos IV. Aportación al catálogo de las provincias de Madrid y Segovia. Anales del Instituto de Botánica Cavanilles, 30: 19-32

Calonge, F.D., Siquier, J.L., Constantino, C. y Lillo, X. (1988). Contribución al conocimiento micológico de las Islas Baleares. I. Gasteromycetes. Boletín de la Sociedad Micológica de Madrid, 13: 139-150.

Calonge, F.D., Santos, J.C., y García, F. (1993). Contribución al estudio de los hongos de Valladolid y provincias limítrofes. Boletín de la sociedad Micológica de Madrid, 18: 59-80.

Calonge, F.D., Caballero, A., y Palacios, J. (1992). Contribución al conocimiento de los hongos de La Rioja (Logroño, España). Gasteromicetes. Boletín de la Sociedad Micológica de Madrid, 16: 115-140.

Calonge, F.D., Siquier, J.L., y Constantino, C. (1992). Contribución al conocimiento micológico de las Islas Baleares. IV. Adiciones al catálogo de Gasteromycetes. Boletín de la Sociedad Micológica de Madrid, 16: 61-72.

Calonge, F.D., Siquier, J.L., y Constantino, C. (1993). Contribución al conocimiento micológico de las Islas Baleares. V. Registro de trece citas nuevas. Boletín de la Sociedad Micológica de Madrid, 18: 105-116.

Cano, F.F. (2003). Aprovechamiento y conocimiento popular de un recurso alimenticio de los montes murcianos: los hongos del género Terfezia. Lactarius, 12: 35-53. 
Casas, J. (2013). Una reflexión sobre la contribución de los montes al desarrollo rural de la España actual. Foresta, 56: 96-107.

Castro, M.L., Freire, L., y Calonge, F.D. (1993). Catálogo provisional de los Gasteromycetes de Galicia (España). Boletín de la Sociedad Micológica de Madrid, 18: 87-104

Castroviejo, S., Aedo, C., Cirujano, S., Laínz, M., Montserrat, P., Morales, R. et al. (eds.) (1993). Flora iberica Tomo 3. Real Jardín Botánico, CSIC, Madrid. 730 pp.

Comandini, M., Contu, M. y Rinaldi, A.C. (2006). An overview of Cistus ectomycorrhizal fungi. Mycorrhiza, 16: 381-395.

Conca, A. García, F. y Martínez, F.P. (2015). Basidiomycetes del Parc Natural de la Serra de Mariola (II). Butlletí de la Societat Micològica Valenciana, 20: 47-172.

Consejería de Economía y Hacienda (Junta de Castilla y León). (2017). Decreto 31/2017, de 5 de octubre, por el que se regula el Recurso Micológico Silvestre en Castilla y León. BOCYL, 194: 41.979-42.009.

Consejeria de Agricultura, Agua y Medio Ambiente (Región de Murcia). (2003). Decreto $50 / 2003$, de 30 de mayo, por el que se crea el Catálogo Regional de Flora Silvestre Protegida de la Región de Murcia y se dictan normas para el aprovechamiento de diversas especies forestales. BORM, 131: 11.615-11.624.

Cuesta, J. (2012). Hongos y setas silvestres en la Comunidad de Madrid. Foresta, 52: 420-431.

Díez J, Manjon J.L. y Martin F. (2002). Molecular phylogeny of the mycorrhizal desert truffles (Terfezia and Tirmania), host specificity and edaphic tolerance. Mycologia, 94: 247-259.
Fernandez, J., Hidalgo, F. y Oyarzabal, M. (2013). Adiciones a la familia Boletinae con listado de especies del Parque Natural de Gorbea y aledaños (Basidiomycota) III. Yesca, 25: 87-110.

Garcia F, Mahiques, R. y Conca, A. (1996). Hipogeus de la Comunitat Valenciana. II. Butlletí de la Societat Micològica Valenciana, 2: 105-127.

García, A. (2004). Catálogo de las setas de la Carbayera de Tragamón. Ayuntamiento de Gijón. Gijón. 52 pp.

García, A. (2013). Adicciones al catálogo de las setas de la provincia de Valladolid (II). Asociación Vallisoletana de Micología. Valladolid. 101 pp.

Gelpi, C. y Arrojo, E. (2013). Hongos y orquídeas de Almaraz. Bellos desconocidos. Centrales Nucleares Almaraz-Trillo. Salamanca. 250 pp.

Global Biodiversity Information Facility (GBIF). [Internet]. [consultado en 2018, septiembre]. Disponible en https://www.gbif.org.

Guzman, B. y Vargas, P. (2005). Systematics, caracter evolution, and biogeography of Cistus L. (Cistaceae) based on ITS, trnL-trnF, and matk sequences. Molecular Phylogenetics and Evolution, 37: 644-660.

Herbario Digital de Criptogamia (HDCJBM) [Internet]: Real Jardín Botánico de Madrid [consultado en 2018, septiembre]. Disponible en: http://www.rjb.csic.es/jardinbotanico/jardin/index. php?Cab=109\&len=es\&Pag=187\&Pag=189\&Pag $=411 \& \mathrm{Pag}=190 \& \mathrm{Pag}=191$

Honrubia, M., Cano, A. y Molina-Niñirola, C. (1992). Hypogeous fungi from southern spanish semi-arid lands. Persoonia, 14: 647-653.

Honrubia, M., Zamora, M., Gutiérrez, A., Morte, A. (2018). Atlas de hongos de la Región 
de Murcia. Consejería de Empleo, Universidades, Empresa y Medio Ambiente. Comunidad Autónoma de la Región de Murcia. Murcia. 616 pp.

Lázaro, B. (1911). Notas micológicas. Colección de datos referentes a los hongos de España. Memorias de la Real Sociedad Española de Historia Natural VII: 287-342.

Llimona, X., Blanco, M.N., Dueñas, M., Gorris, M., Gràcia, E., Hoyo, P. et al. (2000). Els fongs de Catalunya occidental segons les prospeccions recents. II. Acta botánica barcinonensia, 46: 5-29.

Loizides, M. y Kyriakou, T. (2011). Fungi of the Cistus maquis. Field Mycology (12), 1: 14-22.

Lumholtz, C. (1904). El México desconocido. Tomo II. Charles Scribner's Sons. Nueva York. 521 pp.

Mahiques, R., García, F. y Conca, T. (1995). Hipogeus de la Vall d'Albaida i zones limítrofes (València). Butlletí de la Societat Micològica Valenciana 1: 53- 89.

Maire, R. (1937) Fungi Catalaunici. Series altera. Contribution à l'étude de la Flore Mycologique de la Catalogne. Institut Botànic de Barcelona. Barcelona. 128 pp.

Manovel, J.L. (2012). Análisis de la micoflora existente en varias localidades de la Región de Murcia y criterios para su adecuada protección y gestión. Trabajo de fin de grado. Universidad Católica de Ávila. Ávila. 111 pp (más anexo fotográfico).

Marcos, J. (2017). Aportación al catálogo micológico de la provincia de Cuenca III: Basidiomycetes (Boletales). Micobotánica-Jaen, XII (4): 339-359.

Martínez Peña, F. Oria de Rueda, J.A. y Ágreda, T. (2011). Manual para la gestión del recurso micológico forestal en Castilla y León. Junta de Castilla y León. Valladolid. 432 pp.
Mendaza, R. y Díaz, G. (1987). Las setas. Guía fotográfica y descriptiva. Iberduero. Vizcaya. 932 pp.

Moreno-Arroyo, B., Calonge, F.D., Gómez, J. y Pulido, E. (1999). Flora micológica hipogea de andalucía (España). Boletín de la Sociedad Micológica de Madrid, 24: 127-178.

Moreno-Arroyo, B. (Coord). (2004). Inventario Micológico Básico de Andalucía. Consejería de Medio Ambiente, Junta de Andalucía. Córdoba. 678 pp.

Moreno, B., Gómez, J. y Pulido, E. (2005). Tesoros de nuestros montes. Trufas de Andalucía. Consejería de Medio Ambiente, Junta de Andalucía. Córdoba. 348 pp.

Oria de Rueda, J.A., Martín Pinto, P. y Olaizola, J. (2008). Bolete Productivity of Cistaceous Scrublands in Northwestern Spain. Economic Botany, (62), 3: 323-330.

Paz, I., Barrio, L. y Lavoise, C. (2013). Catálogo provisional de hongos hipogeos de Cantabria y posibles fitobiontes asociados. Yesca, 25: 137-166.

Picón, R., Salcedo, I, Olariaga, I. y Sarrionandia, E. (2007). Monitorización de la micoflora de las zonas dunares del litoral vasco (informe). Sociedad Micológica de Portugalete. 123 pp.

Romero de la Osa, L. (1993). Contribución al estudio de los hongos de la Sierra de Aracena (Huelva). III. Boletín de la Sociedad Micológica de Madrid, 18: 135-144.

Rubio, E., Miranda, M.A., Linde, J., Suarez, A., García, F. y Juste, P. (2006). Catálogo provisional de los hongos hipogeos de Asturias y posibles fitobiontes asociados. Revista Catalana de Micología, 28: $1-40$.

Sánchez, F., Honrubia, M. y Torres, P. (1995). Gasteromycetes interesantes en el Sistema Ibérico. 
Boletín de la Sociedad Micológica de Madrid, 20: 269-276.

Siquier, J.L. y Salom, J.C. (2005). Contribució al coneixement micològic de les Illes Balears XIII: el Parc Natural de Mondragó (II) (Santanyí, Mallorca). Revista Catalana de Micología, 27: 1-16.

Siquier, J.L., Salom, J.C., Espinosa, J., EsteveRaventos, F., Llistosella, J. y Gomes, I.S. (2015). Contribució al coneixement micològic de les Illes Balears (Espanya) XXI: Revista Catalana de Micología, 36: 59-98.

Sobrado, C. (1911) Datos para la flora micológica gallega. Boletín de la Sociedad Española de Historia Natural, 11: 475-476.

Setas de Extremadura [Internet]: Sociedad Micológica Extremeña (MICOEX) [consultado en 2018, septiembre]. Disponible en: http://micoex. org/2016/09/17/melanogaster-variegatus/

Tabares M. y Rocabruna, A. (1991). Aportación al conocimiento de los hongos de la Sierra de Collserola y zonas próximas (Catalunya), II. Butlletí de la Societat Catalana de Micología, 14-15: 87-98.

Tejedor, F., Gracia, E., Guillem, S., Lanau, J. M.,
Laborda, R., Bernad, J. J., et al. (2008). Aportaciones al Catálogo Micológico Valenciano (Hipogeos, I) y notas sobre micorrizógenos competidores de Tuber melanosporum. Butlletí de la Societat Micològica Valenciana, 13: 121-155.

Trappe, J.M., y Guzman, G. (1971). Notes on some hypogeous fungi from Mexico. Mycologia, 63: 317-332.

Truffoir.ro [Internet] Brasov: The South-East European Truffle Company. [consultado en 2018, septiembre]. Disponible en https://www.truffoir.ro.

Vidal, J. M. (1991). Contribución al conocimiento de la flora micológica del Baix Empordà y zonas limítrofes (Catalunya). IV. Hongos hipogeos (Zycomycotina, Ascomycotina y Basidiomycotina). Butlletí de la Societat Catalana de Micología, 14-15: 143-194.

Vila, J y Llimona, X. (2002). Noves dades sobre el component fúngic de les comunitats de Cistus de Catalunya. Revista Catalana de Micología, 24: 74-121.

Vila, J y Llimona, X. (2006). Noves dades sobre el component fúngic de les comunitats de Cistus de Catalunya. II. Revista Catalana de Micología, 28: 167-207 